\title{
O CONTEXTO GEOGRÁFICO BRASILEIRO E SUAS TRANSFORMAÇÕES NA POSTURA DO “SER PROFESSOR”
}

\author{
João Paulo Teixeira Viana \\ Aluno do $5^{\circ}$ período do Curso de Geografia da IFRN (Campus Natal-Central)
}

\author{
Alberto A. L. Almeida \\ Mestre em Educação-Professor de Geografia/IFRN
}

\section{Resumo}

O presente artigo visa propor uma análise do contexto histórico da ciência geográfica no Brasil, elencando a postura do "ser professor" ao longo do processo de transformações da Geografia, enquanto disciplina institucionalizada e obrigatória no currículo escolar do ensino público. Como metodologia cientifica foram utilizados levantamentos bibliográficos em publicações tais como livros, artigos e anais. Para tanto, foi necessário ater-se às principais reformas educacionais brasileiras, levando-se em conta os aspectos históricos políticos e socioeconômicos que contribuíram para o desenvolvimento desta ciência. A pesquisa apresenta como objetivo principal relacionar o desenvolvimento da ciência geográfica brasileira e a figura do docente, enquanto mediador do processo de ensino-aprendizagem em sala de aula. Essa pesquisa se justifica pela crescente demanda em compreender o passado das diferentes ciências, e em especial a Geografia, de forma que possa, a partir da análise do passado, compreender o cenário atual, onde o artigo destina um espaço especial para a visão do autor enquanto discente em processo de formação docente da disciplina de geografia, apontando os prováveis cenários com a nova reforma educacional do ensino médio, por fim, mostrando o quanto a ciência geográfica apresenta sua importância para a sociedade e seus desenvolvimento enquanto disciplina e utilidade social.

Palavras-Chaves: Contexto histórico. Ciência Geografia. Ser Professor.

\begin{abstract}
The present article aims to propose an analysis of the historical context of geographic science in Brazil, highlighting the posture of being a teacher throughout the process of transformations of Geography as an institutionalized and obligatory discipline in the school curriculum of public education. As scientific methodology, bibliographical surveys were used in publications such as books, articles and annals. Therefore, it was necessary to stick to the main Brazilian educacional reforms, taking into account the historical political and socioeconomic aspects that contributed to the development of this science. The main objective of the research is to relate the development of Brazilian geographic science and the role of the teacher as mediator of the teaching-learning process in the classroom. This research is justified by the growing demand to understand the past of different sciences, and especially Geography, so that, from the analysis of the past, it can understand the current scenario, where the article assigns a special space for the author's vision as a student in the process of teacher training in the discipline of geography, pointing out the probable scenarios with the new educational reform of high school, finally showing how much geographical science presents its importance to society and its development as a discipline and social utility.
\end{abstract}

Keywords: Historical Context. Science Geography. Be a teacher. 


\section{INTRODUÇÃO}

0 presente artigo tem por intuito abordar o contexto da Geografia enquanto ciência acadêmica, relacionando-a com a disciplina escolar de Geografia, enquanto componente presente no currículo do ensino público brasileiro. Dessa forma, procura analisar as principais transformações vivenciadas no fazer pedagógico do professor de Geografia, ao longo da trajetória dessa ciência enquanto disciplina escolar, bem como as perspectivas que se apresentam no atual cenário dessa disciplina. A pesquisa se justifica pela necessidade de compreender a evolução do processo de ensino de geografia no Brasil, como também entender os diferentes contextos históricos que influenciaram a sua organização enquanto disciplina escolar. Nesta pesquisa será possível construir uma linha do tempo clara e objetiva do desenvolvimento da ciência geográfica no Brasil, desde o seu surgimento, a sua inserção na academia enquanto curso de graduação, a sua constituição como disciplina escolar até os seus contornos atuais. Também serão destacadas as reformas educacionais promovidas pelo Estado Brasileiro, com destaque para a Lei de Diretrizes e Bases da Educação Nacional e seus aspectos inerentes ao ensino de Geografia.

\section{A GEOGRAFIA ENQUANTO PRÁTICA NO BRASIL}

“Nos primeiros anos do período colonial brasileiro, cabia aos jesuítas, prioritariamente, o exercício da atividade docente". Neste contexto, se configurava uma educação regrada na religião, nos ensinamentos cristãos, tanto para os nativos que ali viviam (índios), como para os exploradores (portugueses). Os jesuítas tinham o intuito de passar para seus pupilos o significado do "Amor à Pátria", do respeito dos nativos aos colonizadores; tudo isso através de literaturas poéticas que enalteciam as conquistas portuguesas, e legitimavam a ocupação do território brasileiro, enquanto espaço explorado e vivido. Pode-se inferir então que, apesar de não existir um ensino institucionalizado da Geografia, indiretamente, os seus conceitos eram colocados em pratica.

Convém ressaltar que durante o Brasil- colônia, o período imperial e até mesmo bom parte do período republicano, a educação era volta para os mais ricos e o ensinamento por parte dos docentes era enaltecer esse arranjo social excludente e preparar os discentes para manter essa estrutura e, nesse contexto, os ensinamentos geográficos também serviam a esse propósito. A esse respeito, Chervel (1990, p.187) infere que:

Os grandes objetivos da sociedade, que podem ser, segundo as épocas, a restauração da antiga ordem à formação deliberada de uma classe média pelo ensino secundário, o desenvolvimento do espírito patriótico, etc.; não deixam de determinar os conteúdos do ensino tanto quanto as grandes orientações estruturais.

Neste período, os filhos dos grandes proprietários de terra, comerciantes e demais grupos que detinham o poder aquisitivo, tinham como objetivo profissional o Bacharelado em Direito. Entretanto existiam requisitos básicos para o ingresso neste curso e um destes requisitos era uma prova especifica, na qual eram necessários conhecimentos de Geografia. Além disso, para se tiver acesso a cargos públicos, também eram necessários conhecimentos do tipo "geográfico". Dessa forma, apesar da Geografia não ser sistematizada enquanto disciplina escolar, o conhecimento dos seus conceitos eram requisitos básicos para a inserção do curso de Direito e cargos públicos e, consequentemente, para a ascensão social. 


\section{A GEOGRAFIA E SUA INSTITUCIONALIZAÇÃO NO BRASIL}

Conforme observado no tópico anterior, a Geografia passa a ser um conteúdo/saber de validade reconhecida a partir da necessidade de seu conhecimento para quem pretendia ingressar no curso de Direito. A partir daí a Geografia ganha status de disciplina escolar integrante dos cursos preparatórios para a inserção nos cursos de Direito, o que já ocorria com as disciplinas de Língua Portuguesa e Matemática.

O primeiro estabelecimento escolar que buscou inserir a Geografia como disciplina foi o Colégio Pedro II, em 1837, no qual aparece pela primeira vez no programa de estudos/ conteúdos da escola. A referida instituição era modelo escolar no Brasil e tratou de seguir os paramentos das escolas francesas, as quais já colocavam a Geografia como componente curricular obrigatório, bem antes das unidades escolares brasileiras.

A partir do estabelecimento da Geografia como disciplina obrigatória, em 1837, a mesma passou a estar presente em todas as reformas educacionais brasileiras até os dias atuais. Ela deixa de ser um saber estratégico, necessário para a própria organização do Estado, para alçar o patamar de um saber apropriado pela escola e visado pelos alunos, ainda que se constituísse como um saber enciclopédico, o qual tinha que ser memorizado e cobrado, oportunamente, em testes e provas. Além disso, a postura autoritária do professor e a apresentação de conteúdos deslocados da realidade vivenciada pelos educandos caracterizam o processo de ensino-aprendizagem dessa disciplina, aproximando-a dos preceitos da Geografia Tradicional.

De acordo com Gonçalves e Chaves (1999, p.197)

Deve-se registrar que, do livro de Aires de Casal, "Carografia Brasílica" (1817), "a memorização de fatos e fenômenos desprovidos de significados" 9 foi copiado por vários autores de livros didáticos durante o século XIX10. No século XX, manteve-se, de maneira geral, a mesma concepção quanto ao método de ensinar Geografia. Como exemplo, temos o livro de Cláudio Thomas “Geografia: curso elementar", editado em 1947, composto por 390 questões de perguntas e respostas com "conteúdo essencialmente decorativo".

Dessa forma, a Geografia surge no contexto brasileiro num movimento contrário ao que ocorrera em relação às outras ciências, as quais tiveram seu início nos espaços escolares regulares e em academias, enquanto a Geografia surge no seio de cursos preparatórios, em que os docentes objetivavam capacitar os educandos a fim de se submeterem às provas de vestibulares de cursos de direito.

\section{A GEOGRAFIA COMO PRATICA ACADÊMICA}

Ainstitucionalizaçãoda Geografiacomodisciplinaobrigatórianasescolassecundaristas brasileiras veio acompanhada de uma problemática crucial: a falta de professores para lecionar esta disciplina, até então, indivíduos formados em Direito, Medicina, pesquisadores ou pessoas que se intitulavam com "notório saber", eram os responsáveis por transmitir os conteúdos geográficos A partir disto, o sistema viu a necessidade de criar cursos superiores e formadores de professores de Geografia, o que tornava imperativo institucionalizá-la como saber acadêmico. 
Em 1930, são fundados cursos superiores de Geografia sendo o primeiro na Universidade de São Paulo, juntamente com a faculdade de História e Geografia em diferentes cidades brasileiras, dentre elas, Rio de Janeiro e São Paulo. Estes cursos tinham, em seu quadro docente, professores de nacionalidade francesa, os quais tinham como influência o pensamento de Vidal La Blache, Assim sendo, a Geografia brasileira, em seus primeiros passos acadêmicos, encontra respaldo teórico no método chamado de "possibilíssimo geográfico", o qual, em linhas gerais, preconizava que "o homem também transformava o meio onde vivia, de forma que para as ações humanas, diversas possibilidades eram possíveis, uma vez que essas não obedeceriam a uma relação entre causa e efeito" (La Blache, 1985). Nesse sentido, Rocha (1996, p. 97) infere que:

O modelo educacional adotado no País a partir de então foi o francês, objetivando para cá "transplantar" os ideais de educação, a organização escolar, a forma, bem como o currículo utilizado nas disciplinas. Ao longo do período imperial e, de forma mais discreta, nas primeiras décadas do período republicano o mesmo fato continuou a acontecer. Assim, ao estudar a história das disposições públicas referentes à instrução pública no Brasil Império é necessário considerar, inevitavelmente, a realidade francesa.

Com a institucionalização da Geografia na academia, diversas faculdades abriram cursos de graduação nessa disciplina. Nascia assim uma nova fase para a ciência geográfica, na qual, conforme os pesquisadores, professores e alunos iam buscando e conhecendo novas possibilidades e formas do saber, foi surgindo à ideia de tornar a Geografia um saber "útil" para a sociedade, independente e, como as demais ciências, com um objeto de estudo definido. Vale ressaltar a criação do Instituto Brasileiro de Geografia e Estatística em 1937, órgão de grande importância para o desenvolvimento e planejamento de políticas públicas por parte do Estado, o qual estimulou o surgimento cursos superior de bacharelado em Geografia.

\section{A INSTITUCIONALIZAÇÃO DOS ESTUDOS SOCIAIS (LEI 5692/71)}

Até a década de 1970 do século passado, as reformas educacionais brasileiras eram de cunho micro, não provocando grandes transformações na disciplina de Geografia. Todavia, a lei 5692/71 que fixam Diretrizes e Bases para o ensino de $1^{\circ}$ e $2^{\circ}$ graus, e dá outras providências, ocasionou transformações mais contundentes no ensino brasileiro e, em particular, no ensino de Geografia, ao propor a extinção dessa disciplina e a aglutinação de seus conteúdos, numa disciplina intitulada de "Estudos Sociais", a qual também englobava conteúdos de História, Filosofia e Sociologia, essa reforma fazia parte do programa "integração social" no objetivava o processo de integralização nacional em que a educação as disciplinas faziam parte, passando a se chamar de Estudos Sociais. Segundo Prevê (1988: 47): 
A disciplina de Estudos Sociais deveria ter como enforque a história e organização social e política brasileira, assegurando, em linhas gerais, a unidade política vigente neste período, exaltando o amor à pátria, a concordância e a positividade com as ações que 0 governo ditatorial fazia no Brasil. Segundo Melo, Vlach e Sampaio (2005, p. 17):

Os objetivos fixados pelo Artigo 30 da Resolução número 8/71 definiam que Estudos Sociais deveria fazer o ajustamento crescente do educando ao meio, no qual deve viver e conviver, dando ênfase ao conhecimento do Brasil na perspectiva contemporânea de seu desenvolvimento.

Com relação ao currículo, este tinha por objetivo o humanismo, a formação do homem e suas virtudes, seus direitos e, principalmente, seus deveres dentro da sociedade. Além disso, tinha o intuito de objetivar o surgimento das aptidões dos alunos acerca de qual profissão seguir. Para tanto, o discente tinha a possibilidade de optar, ao final do ciclo secundário, qual carreira/curso seguir, sendo os mais populares o magistério, o técnico em contabilidade e o de administração. De acordo com Melo, Vlach e Sampaio (2005, p. 27):

O Núcleo Comum de matérias, para a Câmara de Ensino, deveria situar-se na perspectiva de todo o Conhecimento Humano sobre suas grandes linhas; para tanto se optou por uma classificação tríplice entre Comunicação e Expressão, Ciências e Estudos Sociais, por acharem mais unificador do que Ciências e Humanidades. Assim, os Estudos Sociais se constituiriam em um elo a ligar as Ciências e as diversas formas de Comunicação e Expressão, colocando, no centro do processo, a preocupação com o Humano.

Em linhas gerais, a intenção da ditadura militar era transformar as disciplinas de grande importância para o senso crítico do educando em algo superficial, no qual a postura do professor era contribuir para manter a ordem e o progresso do governo ditatorial. Neste contexto, a Geografia, ensinada de forma tradicional nas escolas, contribuía para manter os discentes alheios à conjuntura socioeconômica e política de nosso país. Assim sendo, cabia ao Ensino de Estudos Sociais estabelecerem (...).

(...) a integração espaço-temporal e social do educando em âmbitos gradativamente mais amplos. Os seus componentes básicos são a Geografia e a História, focalizando-se na primeira a Terra e os fenômenos naturais referidos à experiência humana, e na segunda, $o$ desenrolar dessa experiência através dos tempos. O fulcro do ensino, a começar pelo 'estudo do meio', estará no aqui-e-agora do mundo em que vivemos e, particularmente, do Brasil e do seu desenvolvimento [...]. A Organização Social e Política do Brasil (incube-se de) [...] preparar ao exercício consciente da cidadania [...], consciência da Cultura Brasileira e do processo de marcha do desenvolvimento nacional... (MINAS GERAIS, 1972:28).

Por outro lado, o processo de formação inicial do docente de Geografia passa a ser alterado, sofrendo um processo de aligeiramento que culminou na criação de licenciaturas de curta duração, ou seja, um indivíduo poderia forma-se em História e Geografia ao mesmo tempo, em um período de apenas 24 meses. 


\section{O RESSURGIMENTO DA GEOGRAFIA BRASILEIRA}

Durante a maior parte do governo ditatorial, a ciência geográfica se torna refém de um sistema educacional que tinha por finalidade legitimar o status quo e reforçar um modelo de desenvolvimento econômico excludente e concentrador de renda. Entretanto, um processo de ruptura passa a ser engendrado, a partir do final da década de 1970, quando surge a (AGB) Associação de Geógrafos Brasileiros, a qual visava discutir e propor novos pensamentos e discutir novos rumos para o ensino de Geografia.

A AGB foi de grande importância para o contexto em que a ciência geográfica se encontrava, tendo em vista que os embates acerca do processo de renovação dessa disciplina encontravam-se bastante acirrados com o recrudescimento da chamada "Geografia Crítica". Nesse contexto, surgem novas maneiras de pensar a Geografia, as quais eram amplamente divulgadas através da publicação de artigos e de discussões em seminários. A esse respeito, Melo, Vlach e Sampaio (2005, p. 67) inferem que:

Os trabalhos sobre ensino de conteúdo, formação docente, mercado de trabalho, discussão curricular, entre outros são cada vez mais presentes, mostrando que muitas pessoas voltam a discutir a problemática do Ensino da Geografia, o que faz com que se organize um encontro específico de Geografia Escolar.

0 primeiro encontro nacional dos professores de Geografia é realizado em Brasília/ DF na década 90 e, a partir daí, tem se tornado, anualmente, em um espaço de debates que conta com a participação de docentes de escolas públicas e privadas, bem como de estudantes de cursos de graduação e pós-graduação e demais profissionais comprometidos com a ciência geográfica, ou seja, surge um espaço aberto de discussão de experiências e vivências e, assim, o fortalecimento da ciência geográfica em todos os seus âmbitos. Conforme afirma Oliveira (1999: 209):

[...] a atuação de grupos que defendiam esses ideais foi limitada durante o período de vigência da ditadura militar que viveu o país após 1964, para só, mais tarde, com o início da abertura democrática, reaparecer e tomar força, mesmo que sob novos rótulos. No caso da nossa disciplina, o movimento de renovação, que durante essa época ficou reprimido e marginalizado, surge, no final da década de 1970, com o nome de Geografia Crítica.

Nesse contexto, surge a partir da década de 1980, um gradual processo de "redemocratização" da Geografia, ainda que os espaços para os debates e questionamentos da ciência geográfica fossem incipientes. O fato é que, paulatinamente, professores e pesquisadores foram sentindo a necessidade de se discutir os rumos da ciência geográfica e de problematizar sobre a real utilidade da Geografia para a sociedade. Como preconiza Melo, Vlach e Sampaio (2005, p. 86):

[...] esta articulação entre os grupos que discutem a Geografia Escolar no Brasil abre oportunidades para novas pesquisas e incentiva os alunos da graduação a problematizarem sua própria formação no mercado de trabalho: a educação. [...] 
[...] Tal dinâmica, que começou no final dos anos 1970 e avançou de maneira extraordinária durante a década de 1980, mostra que a Geografia Escolar começou/recomeçou a provocar reflexões no seu todo e, em suas particularidades, de maneira que em 1999, foram apresentados 280 trabalhos no $4^{\circ}$ Fala Professor - Encontro Nacional de Professores de Geografia, realizado em Curitiba, Paraná, e depois, mais de 500 no $5^{\circ}$ Fala Professor de Geografia, realizado em Presidente Prudente - São Paulo, em 2003.

A partir da década de 1990, a ciência geográfica ganha um novo fôlego, novos contextos sociais, políticos, econômicos e culturais, entre outros, surgem de uma Geografia puramente descritiva, centrada na memorização de conteúdos e dissociada da realidade dos educandos e que não atende mais às novas exigências da sociedade. Dessa forma, a Geografia passa a ser percebida como uma ciência capaz de discutir e promover o debate acerca da realidade que nos cerca, contribuindo para o entendimento de um mundo que, a cada dia, torna-se mais complexo. Além disso, entramos em uma nova era na qual a tecnologia fez surgir novas formas de comunicação que transformaram o modo de vida das pessoas. 0 mundo entra em um processo pleno e crescente da globalização, no qual as distâncias se aproximam e as desigualdades de alastram.

\section{A GEOGRAFIA ATUAL E SEUS CENÁRIOS}

A ciência geográfica atual ganha um patamar de grande destaque. Trata-se de uma disciplina ampla, que consegue estudar, a partir da análise do espaço, diversos acontecimentos, das diferentes gamas de problemáticas existentes. Com ela, é possível a um aluno de um pequeno vilarejo compreender o lugar em que vive e as relações desse lugar com o que acontece em outros lugares do mundo, estabelecendo as conexões entre as escalas local, regional e global. Dessa forma, a Geografia ajuda a explicar todo o processo dessa conexão e trocas de saber do mundo globalizado.

Cabe também salientar as vertentes que a ciências geográficas desenvolveu com seu processo de transformações ao longo dos séculos e que na atualidade encontra-se semeada em diferentes contextos e ferramentas especificas que tenta compreender os diferentes cenários, ressaltando a geografia política, a geografia econômica e a geografia cultural, sendo estes pilares dessa ciência atual, com a finalidade de compreender de maneira objetiva o homem e sua relação com o espaço.

Nessa perspectiva o homem é dinâmico, capaz de atuar sobre o meio, modificando-o. O homem, por meio de sua cultura, passa a ser então, o "agente ativo" na transformação da natureza. Assim, no olhar dessa visão la blachiana, a natureza passou a ser vista com possibilidade de ser transformada pela ação humana. (TONINI, 2003: 51).

Uma Geografia capaz de atingir o que foi proposto acima só é possível com o elo entre academia, docente e escola/aluno. Contudo, a partir do que se encontra proposto na nova reforma do ensino médio, emerge uma série de preocupações tendo em vista que o texto da reforma não garante a obrigatoriedade da oferta da disciplina de Geografia nesse nível de ensino. 
Vale salientar que tal reforma foi alvo de intensas críticas por parte da academia, instituição onde estão concentrados os principais indivíduos pensantes da ciência geográfica brasileira, seja por seu caráter impositivo seja pelo seu propósito de atender as expectativas do sistema empresarial de ensino.

Na realidade da educação brasileira atual e no documento, reafirma-se cada vez mais o modelo de educação com forte presença do capital, com transferência dos deveres do Estado, de serviços essenciais garantidos na Constituição Federal. Um documento que, em sua essência, propõe oferecer e fortalecer uma educação mínima, cujos resultados são definidores dos currículos e da produção de material didático em escala. Uma educação básica no Brasil que se situa "entre o direito subjetivo e o negócio" (FRIGOTTO, p. 54, 2014).

Nessa era de incertezas a mesma apresentou um ápice anterior a proposta da reforma do ensino médio e que tem gerado grandes debates dentro e fora da academia, sendo relacionada à Base Nacional Comum Curricular que visa em linhas gerais nortear o que é ensinado nas escolas do Brasil inteiro, englobando todas as fases da educação básica, desde a Educação Infantil até o final do Ensino Médio.

A proposta apresentada silencia sobre o debate em torno do objeto de estudo da Ciência Geográfica (espaço geográfico, espaço social, organização espacial e produção do espaço). No texto, há uma clara escolha de perspectiva teórico-metodológica a partir de uma categoria/ conceito-lugar, para definir o processo formativo (o sujeito e o mundo, o lugar e o mundo, as linguagens e o mundo, as responsabilidades e o mundo). Torna-se evidente a forma simplista e reducionista ao propor dimensões formativas e, por consequência, os objetivos de aprendizagem no componente curricular Geografia (BRASIL, p. 65, 2015).

Sendo assim, propõem um currículo único, entretanto apresenta grandes problemáticas, principalmente para a ciência geografia, pois propõem que determinado conteúdos seja regional, ou algum deixem de ser discutidos na sala de aula, assim é abandonado às diretrizes curriculares existentes que preconiza a integralização das diferentes áreas. Assim, os cenários cheios de incertezas aumentam para possibilidades alarmantes, uma vez que o ensino está regredindo, algo contrário que as ciências preconizam que é baseado em perguntas e nas transformações do homem, dando lugar para algo superficial, pouco participativo e mecânico.

\section{CONCLUSÕES}

Em suma, o artigo vem mostrar, em linhas gerais, o processo de evolução da Geografia escolar no Brasil, desde seu nascer na colônia até o cenário atual. Ao mesmo tempo, é imprescindível reconhecer que a Geografia sempre esteve em um patamar de grande importância para a sociedade, mesmo que, em alguns contextos, ela tenha sido usada para manter o status quo; mas, para, além disso, ela consegue a partir dos seus processos históricos se transformarem e auxiliar na compreensão da relação sociedade-natureza em diferentes momentos históricos. 
Ao longo desse processo, o papel do professor de Geografia adquiriu diferentes roupagens: em primeira instancia, recorreu-se a um professor que tivesse uma postura da religiosidade, de formação cristã; em seguida, um docente em sintonia com as necessidades do mercado; em terceiro, um professor reprodutor de conteúdos descontextualizados, e, por fim surge a postura de um docente da ciência geográfica com a criticidade e problematização do todo. Dessa forma, o "ser professor" está em constantes mudanças e transformações, na medida em que a própria sociedade se transforma.

E, se fôssemos pensar a postura de um professor de Geografia em um cenário de em crise? Como seria? Vivemos numa era de incertezas e os rumos da Geografia escolar no Brasil não apresentam contornos definidos. Competem a nós, professores, a partir, não apenas do fazer pedagógico em sala de aula, mas também da participação política e da pesquisa científica, nos configurarmos como agentes protagonistas dos rumos a serem trilhados pela ciência geográfica em nosso país.

Observa-se, assim, um novo mundo para a ciência geográfica, no qual estão postas diferentes linhas de pensamento capazes de nortear o trabalho pedagógico do professor. Seja qual for o caminho escolhido pelo professor é indispensável que, a partir dos conhecimentos geográficos, seja possível aos cidadãos (ãs) compreender o espaço e suas formas de organização, bem como a relação sociedade-natureza num mundo em transformação.

\section{REFERÊNCIAS}

1. BRASIL. Ministério da Educação/ Secretaria de Educação Básica. Proposta de Base Nacional Comum Curricular (BNCC) - Setembro de 2015. Disponível em: <www. basenacionalcomum.mec.gov.br>. Acesso em: 30 mar. 2017.

2. CHERVEL, André. História das disciplinas escolares: reflexões sobre um campo de pesquisa. Teoria \& Educação, Porto Alegre, v. 2 pp. 177-229, 1990.

3. GONÇALVES, Juliano R. \& CHAVES, Manoel R. O discurso geográfico escolar brasileiro na década de 1930/1940. Geografia - Curso Elementar (Cláudio Thomas) In: ENCONTRO NACIONAL DE HISTÓRIA DO PENSAMENTO GEOGRÁFICO. I. Anais... Rio Claro: UNESP. 1999. p. 196-199.

4. MELO, Adriany de Ávila. VLACH, Vânia Rúbia Farias. SAMPAIO, Antônio Carlos Freire. História da Geografia Escolar Brasileira: Continuando a Discussão. UFU, Uberlândia - Minas Gerais, 2005.

5. MINAS GERAIS, Estado de. Revista do Conselho Estadual de Educação. Edição Especial. Belo Horizonte, 1972.300p

6. OLIVEIRA, César A.C. de. Considerações sobre a História da Geografia Crítica e seu ensino. In: ENCONTRO NACIONAL DE HISTÓRIA DO PENSAMENTO GEOGRÁFICO. I. Anais... Rio Claro: UNESP. 1999 p.200-206 
7. ROCHA, Genylton Odilon Rêgo da. A trajetória da disciplina geografia no currículo escolar brasileiro (1837-1942). Dissertação de mestrado. Pontifícia Universidade Católica: São Paulo. 1996.

8. PRÉVE, Orlandiana S.D. A participação do Boletim Geográfico do IBGE na produção da metodologia do Ensino da Geografia. Campinas:UNICAMP. 1988. 226p. (Dissertação Mestrado)

9. TONINI, Ivaine Maria. Geografia Escolar: uma história sobre seus discursos pedagógicos - 2. Ed - Unijuí, 2006.

10. VIDAL DE LA BLACJE, Paul.La France de I'Est (Lorraine-Alsace). Paris: Arnand Colin (1982). 